\title{
A Comparative Study of Work Safety Standardization and Civil Aviation Safety Management System
}

\author{
Sun Ruishan \\ Research Institute of Civil Aviation Safety, Civil \\ Aviation University of China \\ RICAS, CAUC \\ Tianjin, China \\ e-mail: sunrsh@hotmail.com \\ Zhao Qiong \\ Research Institute of Civil Aviation Safety, Civil \\ Aviation University of China \\ RICAS, CAUC \\ Tianjin, China \\ e-mail: zhaojoan6@163.com
}

\author{
Liu Junjie \\ Research Institute of Civil Aviation Safety, Civil \\ Aviation University of China \\ RICAS, CAUC \\ Tianjin, China \\ e-mail: billows.liu@126.com \\ Song Wenshan \\ Research Institute of Civil Aviation Safety, Civil \\ Aviation University of China \\ RICAS, CAUC \\ Tianjin, China \\ e-mail: wenshan_song@163.com
}

\begin{abstract}
International Civil Aviation Organization (ICAO) requires enterprises to implement Safety Management System (SMS), and the state has compulsory requirement for Work Safety Standardization at the same time. To improve the efficiency of safety management of enterprises, considering Basic norms for work safety standardization of enterprises (AQ/T9006-2010) and ICAO Safety Management Manual (Doc 9859), the similarities in system architecture, operating foundation, basic objective and top-down safety responsibility as well as the differences in elements, primary focuses, and specific audit methods between Work Safety Standardization System and SMS are comparatively analyzed. The necessity and possibility of integrating two systems are explored, and the approach by integrating the specific requirements of Work Safety Standardization System into SMS in terms of elements, document system and operation according to the corresponding relationship is proposed, which has important guiding significance in establishing and implementing the integrated system in civil aviation enterprises. It can effectively reduce cost and improve the overall level of safety management.
\end{abstract}

Keywords-safety management; Work Safety Standardization; Safety Management System; comparative analysis; integration

\section{INTRODUCTION}

To improve the safety level of the global aviation industry, the International Civil Aviation Organization (ICAO) vigorously promotes safety management system (SMS), which is the latest management mode of safety management in aviation industry [1]. Since 2004, ICAO has promulgated and revised a series of documents on requiring Contracting States to establish SMS. The Annex 6 to the Convention on International Civil Aviation revised in 2006 explicitly stipulates that all Contracting States should require their air operators to implement SMS that can meet the requirements of the aviation authority by
January 1, 2009 [2]. Annex 19 - Safety Management was adopted by the Council on 25 February 2013. This Annex consolidates material from original Annexes regarding safety management systems (SMSs), and it was the firs new Annex in the past 30 years [3]. Civil Aviation Administration of China (CAAC) has also actively promoted the construction of SMS in civil aviation. CAAC requested them to establish a sound mechanism for SMS in 2005 and promoted the construction of SMS across the industry in 2008 [4]. So far, most of the domestic civil aviation enterprises have established SMS.

To achieve the goal of reducing accidents and effectively improving enterprises' level of work safety management and carrying out the guideline of national work safety, the State Administration of Work Safety released the Basic norms for work safety standardization of enterprises (AQ/T9006-2010, hereafter referred to as the Basic norms) in April 2010 [5]. In the document Notice on further strengthening the work safety of enterprises (GuoFa No. [2010]23) released in July 2010, the State Department emphasized the implementation of a comprehensive safety standardization and made a clear and strict rules for carrying out in-depth construction of national enterprises work safety standardization.

Based on the above two systems development backgrounds, SMS is implemented by ICAO, while Work Safety Standardization is a national mandatory requirement. Both of them are essential for China civil aviation industry. SMS and Work Safety Standardization, which are proposed to reduce accidents and ensure safe operations of enterprises, adopt an integrated system architecture. If enterprises use SMS and Work Safety Standardization System (hereafter referred to as WSSS) at the same time, there will inevitably be repetitive work or not unified places during operations, which are bound to get enterprises in trouble. Thus, in order to reduce administration costs, improve management efficiency and 
reduce the overall risk of operators, it is essential to integrate two systems in an effective way, which is the future trend of China civil aviation industry.

\section{COMPARATIVE ANALYSIS OF TWO SYSTEMS}

Firstly, in order to integrate two systems effectively, we should analyze the similarities and differences between WSSS and SMS. The similarities are the foundation of integration and the differences are exactly key points in the integration process.

Considering the 13 primary elements and 42 secondary elements of WSSS required by "5.core requirements" of Basic norms, as well as the four components and twelve elements of SMS described in "5.3 SMS framework" of ICAO Safety Management Manual (Doc 9859), the similarities and differences are analyzed as follows.
$A$. The similarities between two systems

From an overall perspective, WSSS and SMS both are consistent with P (Plan), D (Do), C (Check), and A (Action) dynamic cycle mode. After completing the system construction, enterprises will conduct an internal audit or self-assessment before applying external audit or external assessment [6]. In addition, there are three other similarities.

1) Similar system architecture

WSSS and SMS both adopt the system architecture that manage through elements. The former is composed of 13 primary elements and 42 secondary elements, while SMS framework includes 4 primary elements and 12 secondary elements. Based on the correlation among elements, we can get the corresponding relationship of elements between two systems shown in Table 1 .

TABLE I. CORRESPONDING RELATIONSHIP OF THE ELEMENTS BETWEEN WSSS AND SMS

\begin{tabular}{|c|c|c|}
\hline No. & AQ/T9006-2010 & SMS \\
\hline 1 & 5.1 Objectives & 1.1 Management commitment and responsibility \\
\hline 2 & 5.2.1 Institutional framework & 1.3 Appointment of key safety personnel \\
\hline 3 & 5.2.2 Responsibility & $\begin{array}{l}\text { 1.2 Safety accountabilities } \\
\text { 1.3 Appointment of key safety personnel }\end{array}$ \\
\hline 4 & 5.3 Work safety investment & $\begin{array}{l}\text { 1.1 Management commitment and responsibility } \\
\text { 1.2 Safety accountabilities }\end{array}$ \\
\hline 5 & 5.4.1 Laws and regulations, standard specifications & 1.5 SMS documentation \\
\hline 6 & 5.4.2 Rules and regulations & 1.5 SMS documentation \\
\hline 7 & 5.4.3 Standard operating procedures & \\
\hline 8 & 5.4.4 Assessment /5.4.5 Revision & 3.3 Continuous improvement of the SMS \\
\hline 9 & 5.4.6 Documents and records management & 1.5 SMS documentation \\
\hline 10 & 5.5 Education \& Training & $\begin{array}{l}\text { 4.1 Training and education } \\
\text { 4.2 Safety communication }\end{array}$ \\
\hline 11 & 5.6 Production equipment and facilities & \\
\hline 12 & $\begin{array}{l}\text { 5.7.1 Work site management and work process control } \\
\text { 5.7.2 Operations management } \\
\text { 5.7.3 Warning signs }\end{array}$ & \\
\hline 13 & 5.7.4 Interested parties management & 1.2 Safety accountabilities \\
\hline 14 & 5.7.5 Change & 3.2 The management of change \\
\hline 15 & $\begin{array}{l}\text { 5.8.1 Hidden danger investigation } / 5.8 .2 \text { Investigation } \\
\text { range and methods }\end{array}$ & 2.1 Hazard identification \\
\hline 16 & 5.8.3 Hidden danger governance & 2.2 Safety risk assessment and mitigation \\
\hline 17 & 5.8.4 Forecasting and early warning & \\
\hline 18 & 5.9 Major hazard installations monitoring & \\
\hline 19 & 5.10 Occupational Health & \\
\hline 20 & 5.11 Emergency rescue & 1.4 Coordination of emergency response planning \\
\hline 21 & 5.12 Accidents report, investigation and handling & 2.1 Hazard identification \\
\hline 22 & 5.13.1 Performance appraisal & 3.1 Safety performance monitoring and measurement \\
\hline 23 & 5.13.2 Continuous improvement & 3.3 Continuous improvement of the SMS \\
\hline
\end{tabular}

As can be seen from Table 1, although names and sequence of elements of Work Safety Standardization and SMS are a little different, content of elements have obvious correspondence.

2) Same operating foundation and basic objective

The operating foundations of them are safety risk management. WSSS is carried out by the active hidden danger investigation and SMS implements the active hazard identification to achieve the basic objective of finding out the dangerous and harmful factors in operations and controlling the safety risk, thus meeting safety performance indicators, improving safety management level and ensuring work safety.

3) Emphasizing top-down safety responsibility

WSSS stipulates the responsibility and obligation of enterprises' directors as well as stipulates that enterprises should establish work safety responsibility system to make clear that the work safety responsibility of all units, 
departments and employees. SMS also emphasizes the leadership role, safety commitment and active participation of top management as well as the safety responsibility of employees at all levels. Therefore, both systems emphasize full participation and top-down safety responsibilities.

\section{B. The differences between two systems}

\section{1) Certain differences existing among elements}

In description of specific requirements, there are certain differences among elements of two systems shown in Table 1. Core requirements of Basic norms are basic standards for enterprises constructing WSSS, focusing on the specific process of safety management and emphasizing a kind of standardized safety management system, so specific requirements of implementation are detailed. It focuses on specific guidance at the operational level. While the SMS framework consists of 4 primary elements and 12 secondary elements representing minimum requirements of SMS implementation. Although SMS also requires enterprises to establish a system which could be accepted by authority, it doesn't give specific provisions of elements. It requires enterprises to establish SMS based on their actual situations as well as relevant laws and regulations, so it has wide range of applications and its requirements are relatively broad.

\section{2) Different primary focuses}

WSSS focuses on site management, emphasizing on the standardization of all safety activities and outcomes of safety management. The organization's safety performance evaluation is achieved by auditing outcomes, so it mainly concerns about quantitative outcomes that the safety management can achieve [7]. While SMS focuses on process management, that is organization's safety management process, and it manages a series of elements primarily such as organizational structure, systems, procedures, monitoring and evaluation. SMS mainly concerns about the implementation process, concepts and methods of safety management.

\section{3) Different specific audit methods}

The audit process of Work Safety Standardization System is detailed and specific. The appropriate scoring criteria and methods are established for specific assessment content, and the assessments are based on the criteria item by item. So it is a quantitative evaluation for the organization's overall safety performance [8]. The assessment of SMS is mainly through audit which checks the organization establishment and effectiveness of operations of SMS, and the main audit content is management framework. Audit focuses on the completeness of elements, so it is qualitative evaluation of the elements' conformity [9].

\section{EXPLORATION OF THE POSSIBILITY OF INTEGRATING TWO SYSTEMS}

Throughout the analysis of similarities and differences between the two systems, we can find that they are mutually compatible and complementary during operation. If enterprises establish and operate WSSS alone, there will inevitably be part of the content repeated or not uniform with the requirements of SMS. It wastes corporate resources, disrupts the normal operation of enterprises, and can't reach the effect of improving safety management level [10].
Given the similarities of the two systems in basic objective, operating foundation, management idea and elements design, enterprises can establish WSSS by using various resources such as document system of SMS to avoid the waste of resources and improve the construction efficiency. Therefore, enterprises can take SMS as the main line in the process of integration, that is to say, introduce the materialization and standardization work of management of WSSS into SMS. The integration should be based on elements and document system of SMS to make sure that the elements and documents of two systems achieve integration. Then enterprises can ensure the effective operation of the whole system and continuous improvement of the safety performance through the process management of PDCA circle.

\section{A. The integration of elements and document systems}

According to the contrasting results of elements in Table 1, when integrating two systems, civil aviation enterprises should incorporate the specific provisions of WSSS which is focus on site management into the SMS framework which is focus on process management in terms of their relevance among elements. The integration of elements of WSSS that not included in SMS is shown in Table 2.

TABLE II. THE INTEGRATION OF WORK SAFETY STANDARDIZATION ELEMENTS NOT INCLUDED IN SMS

\begin{tabular}{|c|c|c|}
\hline No. & AQ/T9006-2010 & SMS \\
\hline 1 & 5.4.3 Standard operating procedures & $\begin{array}{l}1.1 \quad \text { Management } \\
\text { commitment and } \\
\text { responsibility }\end{array}$ \\
\hline 2 & $\begin{array}{l}5.6 \text { Production equipment and } \\
\text { facilities }\end{array}$ & $\begin{array}{lrr}2 & \text { Safety risk } \\
\text { management } & \\
\end{array}$ \\
\hline 3 & $\begin{array}{l}\text { 5.7.1 Work site management and } \\
\text { work process control } \\
\text { 5.7.2 Operations management } \\
\text { 5.7.3 Warning signs }\end{array}$ & $\begin{array}{l}1.2 \text { Safety } \\
\text { accountabilities } \\
2.1 \quad \text { Hazard } \\
\text { identification }\end{array}$ \\
\hline 4 & 5.8.4 Forecasting and early warning & $\begin{array}{lrr}2 & \text { Safety } & \text { risk } \\
\text { management } & \end{array}$ \\
\hline 5 & $\begin{array}{l}\text { 5.9 Major hazard installations } \\
\text { supervision }\end{array}$ & $\begin{array}{ll}2.1 & \text { Hazard } \\
\text { identification } & \\
\end{array}$ \\
\hline 6 & 5.10 Occupational Health & $\begin{array}{lrr}2 & \text { Safety } & \text { risk } \\
\text { management } & \\
\end{array}$ \\
\hline
\end{tabular}

Then, considering their own characters, the civil aviation enterprises can take elements integration as the pointcut and integrate document systems by checking leakage and filling a vacancy. For those documents corresponding to the same elements existing in SMS, such as safety policy and objectives, documents and records management, safety accountabilities, safety performance indicators, safety TRAINING and information exchange listed in Table 1, enterprises can directly supplement or modify documents to meet requirements according to specific requirements of WSSS. For those documents corresponding to the unique elements that need to be compiled, such as standard operating procedures, production equipment and facilities shown in Table 2, enterprises should compile new documents and number the records produced during compiling in time. The catalogues should be in accordance with SMS documents format requirements, making sure documents can be referenced by each other. Enterprises must ensure that the document system meets the elements requirements of both systems, 
and there are no repeat, conflicts or reduction of contents after integration [7].

\section{B. The integration of systems' operation}

Both of WSSS and SMS follow the operation mode of "PDCA" dynamic circle, combining with the similarities and differences between two systems analyzed above and the integration thought of elements and document systems, the integration of systems operation can be carried out in the following four stages. In the process, we must fully take all elements of both systems into account and also ensure that the document system meets the requirements on procedure documents and system documents of the two systems. The pointcuts and integrated approach of each stage are as follows:

\section{1) Plan}

The planning stage is an important first step of establishing integration system. At this stage, enterprises should synthetically consider requirements in the planning stage of WSSS on the foundation of that in SMS, by resetting "the institutional framework", adjusting "safety responsibility system", carrying out "identifying and accessing applicable laws and regulations \& standard specifications", formulating "safety policy and objectives", implementing "hazards identification and risks assessment" and "coordination of emergency response planning", as well as developing "risk mitigation measures".

At this stage, enterprises can directly organize the leading group of WSSS by Safety Review Commission of SMS and use the team that has been trained and past the audit in the process of SMS establishment and operation to promote the construction of WSSS, thus making full use of existing resources of enterprises and speeding the construction.

\section{2) $\mathrm{Do}$}

Operation and implementation phase is based on the planning content at last phase, implementing specific requirements of two systems. At this phase, the integration is carried out mainly from eight aspects of "system documents, work safety rules and regulations \& standard operating procedures," "documents and records management," "safety education and training", "safety information exchange", "production equipment and facilities", "operation safety", "inform and control occupational hazards" and "emergency organization, emergency planning, emergency drills and accident rescue".

There are no explicit contents about "production equipment and facilities" and "operation safety" in SMS, so during the process of integration, enterprises should manage the operation and implementation process in accordance with the responsibility, documents, training, communication and other requirements of SMS, while control the specific links such as "production equipment and facilities", "operation safety", "occupational hazard" and "emergency drills and accidents rescue" on the basis of relative requirements in WSSS.

3) Check

The main works at check phase are monitoring and evaluating the effectiveness of system operation, and this phase is integrated from four aspects of "safety performance monitoring and measurement", "forecasting and early warning", "safety checks", "accident, incident investigation and handling \& nonconformance corrective and preventive measures".

At this phase, enterprises mainly make use of safety performance standards that made at the planning phase to measure the safety performance of enterprises, then track implementation and operation of the integrated system through internal assessment, internal audit, external audit, etc. Enterprises can put internal audit work of SMS and independent evaluation work of WSSS together and take the requirements for implementation of safety checks as part of internal audit in the integrated system to improve the operational efficiency. So that enterprises not only achieve the integration at elements and document level, but also combine the internal audit and the specific safety checks process together, thus achieving truly integration management.

\section{4) Action}

Enterprises should take requirements for the continuous improvement process of both systems into account at improvement phase. According the deficiencies and changes in external and external conditions during the establishment of the integrated system, enterprises should develop new system planning programs based on the regular internal assessment results and improve the issues through continuously modifying and perfecting all kind of element requirements, thus ensuring the stable and orderly operation after the systems integration.

\section{CONCLUSION}

(1) Safety Management System is propelled by ICAO and carried out by the international civil aviation industry, while Work Safety Standardization System is a national mandatory requirement. Both of them have the same objectives and are systematic safety management mode, so the effective integration of the two systems is very meaningful.

(2) By comparative analysis of core requirements in Basic norms for work safety standardization of enterprises and specific requirements in SMS written in ICAO Safety Management Manual, it is found that both systems are similar in operating foundation, basic objectives and management ideas. The differences exist in terms of specific content of elements, primary focuses and specific audit methods. Therefore, the two management modes are complementary and also have certain integration basis. The integration of systems in enterprises is feasible and necessary.

(3) Based on Safety Management System framework, this paper incorporates into the specific provisions of Work Safety Standardization System in terms of elements, document system and operating mode. We can conserve resources for the enterprise by effective integration and effectively ensure the safe operation of the enterprise.

\section{REFERENCES}

[1] ICAO. Safety Management Manual (Third Edition) Doc9859/AN474 [Z]. 2013.

[2] CAAC Flight Standards Department. Advisory Circular: Air operator safety management system certification requirements. AC-121/135-2008-26[Z]. 2008.

[3] International Civil Aviation Organization. Annex 19 to the Convention on International Civil Aviation Safety Management [Z], 2013. 
[4] Gao Zhu, Xu Baoguang. Interpretation on the Aviation Safety Management System [J]. Science \& Technology for Development, 2012, (03):11-15.

[5] Basic Norms for Work Safety Standardization of Enterprises [s]. AQ/T9006-2010, 2010.

[6] Zhang Jianye. Probe into utilizing OHSMS to promote work safety standardization construction $[\mathrm{J}]$. Journal of Safety Science and Technology, 2012, (09): 186-189.

[7] Dong Guohua. With OHSMS as the framework developing work safety standardization standard enterprises [J].Navigation, 2013, (04): 74-77.
[8] Zhang Jinsheng. Enterprises develop reaching the standard of work safety standardization implementation-the relationship of work safety standardization and OHSMS [J]. China Science \& Technology Panorama Magazine, 2013, (21): 264-265.

[9] Zhang Feng. Internal audit in civil aviation SMS [J]. China Civil Aviation, 2013, (02):22-23.

[10] WANG Qiquan, TONG Ruipeng. Analysis and probe into implementing safety quality standardization in aviation industry [J]. China Safety Science Journal, 2005, 15(12): 47-51 